\title{
The Effect of Meeting Opportunities on Local Urban Residents' Prejudice against Migrant Children in China
}

Jaap Nieuwenhuis (jaap_nieuwenhuis@,zju.edu.cn)

Xinyi Shen (xyshen@,zju.edu.cn)

Zhejiang University, Department of Sociology

This is the authors' pre-print version (final draft pre-refereeing). This version is available as: Nieuwenhuis, J., \& Shen, X. (2021). The Effect of Meeting Opportunities on Local Urban Residents' Prejudice against Migrant Children in China. SoxArXiv, doi:10.31235/osf.io/q4pg7. Link: https://doi.org/10.31235/osf.io/q4pg7.

CC-By Attribution-NonCommercial-NoDerivatives 4.0 International

\begin{abstract}
This article explores the effect of meeting opportunities between local urban and nonlocal residents on locals' prejudice against migrant children in China by focusing on three contexts: friendships, schools, and neighborhoods. China's hukou policy creates a boundary between urban and rural residents, which also takes the form of locals and nonlocals in rural-to-urban migration. Urban public schools with a mix of local and migrant students offer a chance to observe the intergroup relationships between local and nonlocal students as well as their parents. Using the two waves of data of the China Education Panel Survey (CEPS), this study examines how changes in the migrant friends, schoolmates, and neighbors of local children affect changes in their parents' prejudice among a sample of 1,630 student-parent pairs. With longitudinal data, this study mitigates the effect of reverse causality between intergroup contact and prejudice. The findings show that parents whose children have more migrant friends have less prejudice, under certain conditions. Additionally, more nonlocal students in the school are related to less prejudice, especially among parents who are more embedded in the school. Furthermore, local families with low socioeconomic status experience an increase in prejudice, potentially due to an increased feeling of threat. Besides, this article finds that prejudiced attitudes spread through the social networks of children and parents at the school level. This study emphasizes the importance of different contexts of meeting opportunities and sheds new light on the generalizability of the contact hypothesis to the understudied context of Chinese internal migration.
\end{abstract}

Keywords: China; internal migration; contact hypothesis; social learning; prejudice 


\section{Introduction}

Internal migration has been a topic of heated discussion for more than forty years in China. Since the reform and opening-up policy of 1978, mobility within China has become much easier. Internal migration, specifically rural-to-urban migration provided an abundant labor force and made important contributions to the development and construction of Chinese cities (Fan 1999; Guang 2005). In 2017, the mobile population reached 244 million people, which was $17.6 \%$ of the total population in that year (UNICEF 2017). While the restrictions on population mobility have been gradually eased, the institutions that were once designed to manage mobility have not yet been abolished. The household registration system (hukou system) not only divides the population into urban and rural residents, but is also directly related to the distribution of resources and welfare policies ( $\mathrm{Lu}$ and Zhou 2013; Solinger 1999; T. Wang 2020), which includes the right to enroll in local schools. There were more than 14 million migrant children who were supposed to engage in compulsory education in 2017 (Li 2018), which makes education for migrant children a significant social issue. Attention was given to this issue much later than the implementation of the opening-up policy of mobility. It was not until 1998 that the Ministry of Education began to address this problem with a law passed allowing urban schools to incorporate migrant children (L. Wang 2008). In 2001, the central government stressed that the solution to this problem calls for local governments and public schools to take responsibility (Lu and Zhou 2013; L. Wang 2008; Chen 2008). Shanghai was the first city to take action. In 2008, it was the first city in China to incorporate migrant children into local public schools. Prior to this, migrant children could only study in informal private schools made up of only migrant children. Many cities followed Shanghai's example (Lan 2014). However, in cases where hukou status no longer restricts access to schools, the distinction between local and nonlocal, or urban and rural, might still occur in more subtle forms. Group boundaries might dictate social relationships and locals might have prejudices against nonlocals and discriminate against them (Feng 2002; Kwong 2011; Lan 2014; Lu and Zhou 2013). Schools that mix local and migrant children give local and migrant children and their parents an opportunity to meet and interact. This makes these schools an important context in which to study the interaction and meeting opportunities between members of the two groups.

The distinction between local and migrant students can be linked to an important research approach in social psychology. Since Allport (Allport 1954), the inquiry into the causes of prejudice has focused on intergroup relationships, which is distinct from the research focusing on interpersonal relationships. Following this research approach, Tajfel and Turner established social identity theory (Tajfel and Turner 1986), which argues that the basis of intergroup behaviors is knowledge of the membership of the group to which people belong. Applied to the context of internal migration in China, the institution of the hukou system generated two groups: locals and nonlocals. Although its original meaning merely relates to urban administration and resource distribution, the media and scholars developed its meaning in cultural and identity aspects by constructing a narrative system, which in turn shaped the stereotypes of local residents towards migrant people (Pan 2007). Prejudice towards migrants, especially migrant workers, has not receded until now, and has pervaded to various fields, including schools (Kwong 2011; L. Wang 2008). In schools, the long-existing stereotypes of the contrast between 
locals and nonlocals might be altered through the direct interaction between local and migrant children and their parents (Allport 1954; Li et al. 2010). This intergroup contact might increase local people's knowledge about and empathy towards migrants and reduce anxiety (Pettigrew and Tropp 2008). This may result in reduced prejudice against migrants, suggesting that the different opportunities local parents have to meet migrants will positively alter their prejudice against migrants.

In this article, we explore local urban residents' prejudice regarding how migrant children in schools affect the quality of education and the atmosphere in class using two waves of the China Education Panel Survey (CEPS). More specifically, we are interested in how contact opportunities between local parents and migrants shape local parents' prejudice against migrant children. We focus on three contexts of meeting opportunities, including friendships, schools, and neighborhoods, which are rarely tested altogether in previous studies (Nieuwenhuis, Kleinepier, and van Ham 2021). We use the understudied case of China (Kende et al. 2018) to add a relatively new perspective to the study of meeting opportunities and prejudice, thereby shedding new light on the generalizability of the mechanism.

\section{Literature review}

\section{Revisiting the "contact hypothesis"}

It should be emphasized that the construction and development of social identity is based on a cognitive tendency to exaggerate differences between different groups and to underestimate the variability in the characteristics of the out-group, thereby strengthening the self-esteem of the in-group (Brown 2010; Tajfel 1982). When people favor their own group, they have a predisposition to allocate scarce resources to their own group. Therefore, competition arises between groups, potentially resulting in prejudice and conflict, which in turn increases in-group favoritism, resulting in a negative spiral (Scheepers, Gijsberts, and Coenders 2002).

However, intergroup relationships do not necessarily have to be a cause of conflict but can also be a cure to fix between-group tensions. Long before the development of social identity theory, the conditions under which intergroup prejudice can be reduced were explored by Allport (1954). Allport's "contact hypothesis" predicts that increased intergroup contact results in increased knowledge of the other group, which results in a better understanding of out-group members, therefore reducing prejudice. Allport's contact hypothesis predicts reduced prejudice between groups only if the following conditions are satisfied: equal status, mutual goals, intergroup cooperation, and support from authority and law. Later studies showed that they are more likely to be catalysts than necessary conditions (Pettigrew 1997; Pettigrew and Tropp 2006), which broadened the conditions under which the effect of contact on prejudice can take place.

Further studies examined the effect of contact from different perspectives. For example, the quality of contact is significantly related to attitudes towards ethnic groups (Stephan, Loving, 
and Duran 2000), contact mediates the relationship between immigration background and the perceived threat of local residents (McLaren 2003), and even imagined integration can mitigate prejudice towards other groups (Crisp and Turner 2009). A large meta-analysis of 515 studies showed that the general consensus is that there is a negative relationship between intergroup contact and prejudice (Pettigrew and Tropp 2006). Meanwhile, this study extended the application of the contact hypothesis by stressing its generalizability to other out-groups, besides only ethic groups (Pettigrew and Tropp 2006). Moreover, positive contact with one individual from the out-group can make a difference for prejudice or stereotypes towards the entire group (Amichai-Hamburger and McKenna 2006). Therefore, when studying the prejudice between locals and nonlocals in the Chinese context of internal migration, the contact hypothesis will likely prove very useful.

In order to explore the underlying mechanisms of the contact hypothesis, two things have been done by scholars. First, researchers found several mediators between contact and prejudice: 1) knowledge about the out-group, 2) anxiety about the out-group, and 3) taking the perspective of out-group members and empathizing with them. Of these three, anxiety and empathy appear to be the most important (Pettigrew and Tropp 2008). Second, the reverse causality of contact and prejudice should not be neglected. People may have more contact with out-group members because they were already less prejudiced. Methods that can address this problem include experiments and longitudinal studies (Laar et al. 2005; McLaren 2003; Pettigrew 1997, 2008). The present study uses longitudinal data to study changes in prejudice and therefore has an advantage over the more common cross-sectional studies.

Despite many confirmations of the contact hypothesis and efforts made towards more integrated societies, in reality, conflict and prejudice between different groups still exist, even when they have opportunities to meet each other (Dixon, Durrheim, and Tredoux 2005; Stephan 1978). This dilemma calls for rethinking the contact hypothesis. One of the reflections focuses on the variability of contact. Studies have emphasized the quality (Stephan, Loving, and Duran 2000) and meaning (Valentine 2008) of contact. Another study suggested focusing on the effects of negative contact (Pettigrew 2008). Negative contact with out-group members will strengthen the salience of in-group identification, thereby facilitating prejudice. Furthermore, negative contact has a stronger effect than positive contact (Barlow et al. 2012; Paolini, Harwood, and Rubin 2010). These findings remind us to examine the effects of contact more carefully. A recent study shows that Chinese urban locals and rural nonlocals who move into the same neighborhood and thus have meeting opportunities can still be hostile and prejudiced towards each other (Du, Song, and Li 2020).

\section{Three contexts of contact}

There are many studies examining the role of contact in different contexts, such as contact in the form of friendships, coworkers, schoolmates, neighbors, etc. Different situations offer different social norms for intergroup contact. The following review focuses on three specific contexts: friendships, neighborhoods and schools. These contexts vary in the types of contact people have within them. For example, friendships are inherently more intimate while 
relationships in neighborhoods and schools are often more casual (Amir 1969). In all three contexts, intergroup contact can be direct, meaning that individuals themselves have out-group contact. However, individuals can also be influenced by indirect contact, which occurs when they know in-group members that have out-group contacts (Hewstone et al. 2005). All three contexts provide opportunities to observe indirect intergroup contact.

Friendships. Among the three contexts, friendship is the most tested. Researchers argue that friendship is an intimate type of contact that has a significant effect on attitudes towards outgroup members compared to more casual contacts (Amir 1969; Ellison, Shin, and Leal 2011). Friendship is also the type of contact closest to the "optimal conditions" that Allport (1954) raised because it is equal and voluntary (Pettigrew 1997). Intimate contact in the form of friendships with nonlocals can reduce the perceived threat and exclusionary feelings of local people (McLaren 2003). Furthermore, through the mechanisms of empathy, identification with the out-group and reappraisal of the in-group, having cross-group friendships may make local people more favorable towards pro-migration policies and towards nonlocals in general (Pettigrew 1997).

However, focusing on friendships can have drawbacks, because friendships can only have an effect when people have opportunities to meet each other (Turner et al. 2008). More studies started to extend the contact effect by arguing that even no contact can have a negative relationship with prejudice. Specifically, when people know that their in-group members make friends with out-group members, their attitudes towards out-group members can improve (Turner et al. 2008; Wright et al. 1997; Zhou et al. 2018). This perspective sheds new light on the intergroup relations literature; and as for the present research, although the parents of local students may not make friends with nonlocal students and their parents directly, their attitudes towards them can improve under noncontact conditions. A meta-analysis has shown that for this extended contact hypothesis, in-group members' attitudes towards out-group members improve when they believe in the existence of cross-group friendships, even when this information may be inaccurate (Zhou et al. 2018). Therefore, extended contact may have an effect on local students' parents when they perceive their children's cross-group friendships with nonlocals.

Schools and neighborhoods. Compared to cross-group friendship, not only are the effects of contact in schools and neighborhoods less often tested, the existing literature is more variable and inconclusive. Among the existing studies, some argue that intergroup contact in these contexts does not significantly mitigate prejudice (Du, Song and Li 2020; Kwong 2011; Wagner, Hewstone, and Machleit 1989) while others occasionally find a positive influence of contact in schools and neighborhoods (Laar et al. 2005; Pettigrew 1997).

In ideal situations, intergroup contact in schools and neighborhoods can facilitate people from different groups getting to know each other and subsequently reduce levels of anxiety towards members of the other group. However, such contact opportunities do not necessarily reduce prejudice. The actual opportunities to meet out-group members and the potential for contact in schools and neighborhoods to generate friendships are important. First, meeting opportunities in these contexts do not necessarily lead to actual contact. Although local and nonlocal 
students/residents might be in the same schools/neighborhoods, the two groups of people may not actually mix with each other; and therefore, the opportunities for them to interact with each other might be constrained (Kwong 2011; Stephan 1978; Wagner, Hewstone, and Machleit 1989). Second, meeting opportunities are related to reduced intergroup prejudice. For example, different opportunities for contact resulted in different outcomes in West and East Germany. In schools and neighborhoods, contact between locals and foreigners could reduce locals' prejudice towards out-group members, but only in West Germany because people in West Germany had more foreign friends and perceived these contacts as more important (Wagner, Dick, Pettigrew, and Christ 2003). Moreover, this study found that contact opportunities in schools and neighborhoods can reduce prejudice because of their potential to generate crossgroup friendships (Wagner et al. 2003), suggesting that it is cross-group friendships that truly matter. A situation's potential for friendship is even treated as the essential condition of optimal intergroup contact (Pettigrew 1997). The findings above remind us to consider the strength of social relationships when studying the contact hypothesis in schools and neighborhoods.

Furthermore, in the school context, attention should be given to peer influence among students. Social learning theory states that people have a tendency to learn from the opinions and behaviors of others in their environment (Bandura 1977). Especially in the contexts of families and schools, opinions will be transmitted from parents to children and among students (Dohmen et al. 2011). Therefore, it is reasonable to predict that attitudes such as prejudice can also spread throughout schools. When parents in a school have prejudiced attitudes towards nonlocals, these attitudes may spread through social networks, including students and parents (Christakis and Fowler 2013). Individuals who did not hold prejudiced attitudes may adopt them because they meet other parents in the school who are prejudiced or even observe discriminatory behavior (Bandura 1977). Previous studies have shown evidence for students' behaviors and attitudes being "contagious" in peer groups for many aspects, such as engagement in classes (Mendoza 2020), beliefs about the malleability of intelligence (King 2020), and sense of well-being (Datu 2017). Besides, one study argues that peer groups may affect individuals' homophobic attitudes and support for social hierarchy (social dominance attitudes) (Poteat, Espelage and Green 2007). How the contextual factors of social networks of students and parents in schools can affect the prejudiced attitudes of local parents towards nonlocals is seldom discussed but important to understand group dynamics within Chinese schools.

In the neighborhood context, being surrounded by nonlocal residents may have different effects on local residents according to their socioeconomic status (SES). When social resources, such as employment, are limited and scarce, people will have to compete for them (Nieuwenhuis and Hooimeijer 2016). Under such circumstances, people will generally favor in-group members, potentially leading to increased prejudice towards out-group members (Scheepers, Gijsberts, and Coenders 2002; Sherif 1988). Most nonlocals in Chinese cities migrated from poor areas of the country to perform low-skilled jobs in cities (Ling 2015). Low-skilled jobs require people with low education, pay a low income and are more unstable than high-skilled jobs. Low-skilled local workers in cities may therefore feel more threatened by the presence of nonlocals in their neighborhood because they personally experience the competition for scarce goods, such as local employment (Nieuwenhuis, Völker, and Flap 2013; Scheepers et al. 2002; Yang et al. 
2010). Conversely, people with higher education and higher salaries are in different job markets from most nonlocal workers and are more likely to be aware of the contributions of nonlocal workers instead of feeling threatened by them (Yang et al. 2010).

\section{The current study}

Previous research has shown how prejudice and conflict may occur due to intergroup relationships and has proven that positive contact can reduce intergroup prejudice. Even the prejudice of people who are not directly involved in intergroup contact can potentially be reduced when they observe that other members of their own group have positive contact with out-group members (Pettigrew 1997; Pettigrew and Tropp 2006). Furthermore, many studies linking contact to prejudice are based on cross-sectional data and are unable to address topics such as reverse causality (Pettigrew 2008). Additionally, the potential role of negative contacts is understudied (Pettigrew 2008). Finally, there are many studies focusing on different contexts in which contact may affect prejudice differently, but few of them have examined several contexts together.

The current study uses two waves of CEPS to test the contact hypothesis in a relatively understudied context, i.e., China. Prejudice from local urban residents towards nonlocal migrants can threaten the social cohesion within Chinese cities; therefore, studying whether meeting opportunities between the two groups may facilitate more mutual understanding and less prejudice will provide a better understanding of social integration in Chinese cities. Using longitudinal data, we can mitigate the influence of reverse causality by studying the relation between changes in social contexts and changes in prejudice. Furthermore, we contribute to the literature in two ways: first, we examine the effects of contact in three different contexts together, including friendships, schools and neighborhoods; and second, we test whether intergroup contact can affect other in-group members in that changes in local students' intergroup contact will affect their parents' prejudice. In that sense, we hypothesize that when local urban residents have more opportunities to meet nonlocals, they will have lower levels of prejudice against nonlocals. Besides, we argue that people who are more embedded in the context where they have meeting opportunities will be more strongly affected by this context; therefore we formulate two related hypotheses. First, the negative effect of opportunities to meet nonlocals in schools on prejudice against nonlocals will be stronger for people who are more involved in their child's school. Second, the negative effect of opportunities to meet nonlocals in friendships on prejudice against nonlocals will be stronger for people who have knowledge about their child's friends' parents. The latter hypothesis is also consistent with the extended contact hypothesis from which we can derive that although local students' parents do not make friends with nonlocal students directly, their prejudice can be reduced when they perceive these cross-group friendships and recognize their importance. Furthermore, the effects of contact may vary for people with different socioeconomic statuses because low SES locals may feel more threatened in their employment by the presence of low SES nonlocals than high SES locals would (Hello, Scheepers, and Sleegers 2006; Yang et al. 2010). Therefore, we hypothesize that the effect of opportunities to meet nonlocals in neighborhoods on prejudice against nonlocals will be negative for high SES individuals and positive for low SES individuals. 
Finally, we expect prejudiced attitudes to be "contagious" among locals' social networks. For example, when enough people hold prejudiced views against nonlocals, other locals will also adopt these views. We hypothesize that the more prejudice against nonlocals all parents in schools hold, the higher people's individual-level prejudice will be.

\section{Data and methods}

\section{Participants}

To test our hypotheses we used the China Education Panel Survey, a nationally representative, longitudinal dataset of students, parents, teachers, and school administrators. The first wave of data was collected in the 2013-2014 academic year with a sample size of approximately 20,000 7th and 9th grade students nested in 438 classrooms of 112 schools in 28 county-level units in mainland China. We only used the 7th grade students and their parents for whom there was a second wave of data available for the 2014-2015 academic year (10,279 students). Because we are interested in changes in the attitudes of parents, we selected only those parents who completed the questionnaire at both time points and excluded respondents who did not. Furthermore, we only selected individuals with a local hukou who lived in an urban area. Finally, because we are interested in changes in meeting opportunities with nonlocals, we only selected schools that enrolled nonlocal students during at least one of the measurement points. These selections resulted in a reduced sample of 2,216 student-parent pairs. We used pairwise deletion to handle missing data, resulting in a final sample of 1,630.

To test whether the probability of missingness was associated with our outcome variables, we ran several t-tests (Allison 2002). The following variables were missing at random: change in nonlocal friends $(\mathrm{t}=-.2632, \mathrm{df}=2214, \mathrm{p}=.7924)$, change in migrants in the neighborhood $(\mathrm{t}$ $=-1.1569, \mathrm{df}=2214, \mathrm{p}=.2474)$, (non)agricultural hukou $(\mathrm{t}=.6623, \mathrm{df}=2214, \mathrm{p}=.5078)$, parental education $(\mathrm{t}=.7572, \mathrm{df}=2207, \mathrm{p}=.4490)$, family SES $(\mathrm{t}=-1.0249, \mathrm{df}=2117, \mathrm{p}$ $=.3055)$, parental sex $(\mathrm{t}=.6486, \mathrm{df}=2171, \mathrm{p}=.5166)$, and student $\operatorname{sex}(\mathrm{t}=-1.5159, \mathrm{df}=2214$, $\mathrm{p}=.1297)$. The following variables were not missing at random: missing respondents were more likely to change to a school with fewer nonlocals $(t=5.3129, \mathrm{df}=2020, \mathrm{p}<.0001)$ and less likely to have a decline in the school-average prejudice regarding how nonlocal students affect the quality of education $(\mathrm{t}=-7.1738, \mathrm{df}=2214, \mathrm{p}<.0001)$ and the atmosphere in class $(\mathrm{t}=-3.9427, \mathrm{df}=2214, \mathrm{p}=.0001)$. Finally, missing students were slightly older on average $(\mathrm{t}$ $=-4.5543, \mathrm{df}=2156, \mathrm{p}<.0001)$. The results for these variables need to be interpreted with caution.

\section{Variables}

Our two outcome variables are local residents' changes in prejudice regarding how nonlocal students affect educational quality and the atmosphere at school. These were measured with the questions "What kind of effect do you think will the increase of students from nonlocal county/district have on the educational quality of the school/atmosphere of the school?" with 
the answers "beneficial", "no effect", and "harmful". The questions were asked in both waves and subtracted from each other to form a scale from -2 to 2 , where a negative number means respondents became less prejudiced over time and a positive number means they became more prejudiced. The descriptive statistics for these and other variables can be found in Table 1.

\section{--- Table 1 about here ---}

To study how respondents' prejudice could be influenced by the prejudice of others, we aggregated both of the abovementioned indicators of prejudice at the school level. We then took the difference between the two waves for both measures of prejudice to create a variable of school-level change in prejudice.

Next, we created three variables for change in contextual meeting opportunities with nonlocals, for friendships, the school, and the neighborhood, using a multiple responder approach. First, for friendships, the students were asked to name up to five best friends and some of their characteristics, including their best friends' hukou status. For both waves we counted the number of nonlocal friends students possessed and took the difference between the two waves to measure the change in nonlocal friends. Second, for the school, the school administrator was asked the percentage of students with a nonlocal hukou in both waves. The two waves were subtracted from each other to create a school-level variable measuring a positive change in nonlocal students in the schools. Third, for the neighborhood, the parents were asked in both waves in which type of neighborhood they lived in, and they could check all demographics that applied to their neighborhood, including "migrant workers". We created a variable with three categories measuring whether parents marked "migrant workers" in wave 1 but not in wave 2 (fewer migrants), vice versa (more migrants), or whether they gave the same answer in both waves (stable).

To measure how embedded parents are in the social contexts, we created two variables in wave 2. First, to measure embeddedness in school, we measured parental involvement in school with the question "How many times have this child's parents contacted the teacher at school this semester?" with answers 0) never, 1) once, 2) two to four times, and 3) five times or more. Second, to measure parental embeddedness in the context of their children's friendships, we used the question "Do you know the parents of the friends who often play together with this child?" with the three answers "No, I don't", "Yes, I know some of them", and "Yes, I know all of them". We dichotomized this to 0 ) no and 1) yes.

The control variables include hukou status, family SES, parental education, parental sex, students' sex, and students' age. Because we only study the prejudice of parents with a local hukou, hukou consists of local agricultural and local nonagricultural. Family SES stratifies families into poor, middle, and rich. Highest parental education is used as a continuous variable with the following values: 1) none, 2) elementary school, 3) junior high school, 4) technical (secondary) school, 5) vocational high school, 6) senior high school, 7) junior college, 8) bachelor's degree, and 9) master's degree or higher. Parental and students' sexes are coded $0=$ female and $1=$ male. Finally, students' age is measured in years. 
To study how changes in meeting opportunities and school-aggregated prejudice affect changes in individual prejudice against nonlocals in urban China, we conducted regressions for two measures of prejudice regarding how nonlocal students affect the educational quality and the atmosphere at school. Because we study school-level indicators and the data were collected in schools, individuals nested within the same school might not be independent of each other. To account for this, we clustered the standard errors within 73 schools. Then we conduct two sets of analyses. In the first analysis, we study how changes in meeting opportunities in different contexts and school-aggregated prejudice relate to changes in individual prejudice. In the second set of studies, we include the interaction effects with contextual embeddedness and family SES.

\section{Results}

We drew a chart to obtain a general overview of the different levels of prejudice per context. Figure 1 shows the average levels of prejudice in wave 1 for different contextual conditions. The chart shows that for schools with zero to 24 and 25 to $49 \%$ of nonlocal students, the levels of prejudice are similar; but for schools with $50 \%$ or more nonlocal students, parents have relatively higher levels of prejudice. For parents whose children have none or some nonlocal friends, the levels of prejudice are rather similar, although it is slightly higher for parents whose children have one nonlocal friend or more. For respondents living in neighborhoods with or without migrant neighbors, the levels of prejudice are again rather similar, although they are slightly higher for people living in neighborhoods with migrants. Although negligible, the general trend is that when the local respondents have more opportunities to meet with nonlocals, they have higher levels of prejudice.

\section{--- Figure 1 about here ---}

Our hypotheses go further than the descriptive results of Figure 1 because we are interested in how changes in contextual meeting opportunities relate to changes in individual-level prejudice. We first ran the two models for the main effects of meeting opportunities and contextual prejudice on the two indicators for individual-level prejudice (Table 2). The results appear very similar for both outcome variables. When there was a change towards a larger share of nonlocal students attending the school of respondents' children between waves 1 and 2, respondents had a reduction in their levels of prejudice regarding how nonlocal students affect the educational quality and the atmosphere at school. These results were not found for the other two contextual variables regarding meeting opportunities: if respondents' neighborhood had more or less migrants living there, this did not change their level of prejudice; and when respondents' children had more or less nonlocal friends, their prejudice did not change. Furthermore, respondents were strongly affected by changes in the average level of prejudice at the school level. When parents became more prejudiced against nonlocals at the school level, respondents also became more prejudiced against nonlocals. Finally, the control variables indicate that 
higher educated individuals became less prejudiced over time.

--- Table 2 about here ---

Next, we tested our hypotheses about embeddedness in the context and competition by including three interaction effects (Tables 3 and 4). Model 1 in both tables includes the interaction between the change in nonlocal students in school and parental involvement in school. The results are the same for both outcome variables, namely, that the main effect of the change in nonlocal students in school becomes insignificant while the interaction term is significant and negative. This means that the reduction in prejudice caused by a change towards more nonlocal students in school is only present for parents who are involved with the school and not for uninvolved parents. Model 2 in both tables includes an interaction between the change in the number of nonlocal friends respondents' children possess and whether people know the parents of their children's friends. The interaction term is significant and positive for both outcomes; and the variable measuring a change towards more nonlocal friends becomes negative, albeit only significant in the model for the outcome relating to prejudice regarding the atmosphere at school. This indicates that when respondents' children possess more nonlocal friends, respondents become less prejudiced, but only when they do not know their children's friends' parents. Perhaps respondents who know their children's nonlocal friends' parents might be less prejudiced to start with and therefore new nonlocal friends do not affect levels of prejudice. Additional inspection of the data shows that respondents who know their child's friends' parents have, on average, a lower level of prejudice in wave 1 (1.05 on a scale from 0 to 2) than respondents who do not (1.10). Finally, model 3 includes the interaction between the change in migrants in the neighborhood and family SES. This interaction is only meaningful for the outcome variable pertaining to prejudice relating to educational quality. The results suggest that 1) when rich families experience a change towards fewer migrants in their neighborhood, respondents become more prejudiced; and 2) when poor families experience a change towards more migrants in their neighborhood, respondents also become more prejudiced.

--- Table 3 about here ---

--- Table 4 about here ---

\section{Conclusion and discussion}

Since Shanghai was the first city in China to mix local urban and migrant students in public schools in 2008, the issue of intergroup interaction between local and nonlocal students became an important issue. Despite the loosening of the hukou policy together with the easing of schooling restrictions for migrant children, the long-standing group boundaries between locals and nonlocals have not disappeared (Feng 2002; Lu and Zhou 2013). It is of great significance to concentrate on the understudied topic of intergroup contact and prejudice in the context of Chinese internal migration and examine how to mitigate local urban residents' prejudice 
towards migrants. The first objective of this study was to examine the effect of intergroup meeting opportunities of local urban students' parents in their prejudice towards migrants in three different contexts: friendships, schools, and neighborhoods. Furthermore, in order to test the role of different meeting opportunities in more detail, we hypothesized that the effects of contact on prejudice are stronger among parents who are more embedded in the school and know the parents of their children's nonlocal friends. In addition, inspired by social learning theory, we predicted that prejudiced attitudes may spread through the social networks of students and parents. Our second objective was to generalize the contact hypothesis to the context of Chinese internal migration, which has received limited attention in this field but is of great significance (Kende et al. 2018). Different from studies on intergroup contact between urban residents and rural migrants in China, most of which concluded that internal migration strengthened the group boundaries between these two groups and led to increased prejudice towards nonlocals (Du et al. 2020; Li et al. 2006; L. Wang 2008), this study finds that intergroup contact between locals and nonlocals can reduce prejudice. However, we also found that prejudice increased under conditions of potential negative intergroup contact, namely, for poor local families who might feel threatened by the potential competition for scarce local resources such as jobs or housing. When we studied the cross-sectional levels of prejudice for our sample, we saw that more meeting opportunities in all three contexts relate to more prejudice, which would be in line with beforementioned studies on China. However, where previous studies only used static, cross-sectional levels of prejudice, we also studied how changes in intergroup contact relate to changes in prejudice. By this, we provide stronger evidence of the actual relation between intergroup contact and prejudice against nonlocal migrants.

Our findings clarify the effect of meeting opportunities of local urban students' parents on their prejudice towards nonlocals in three contexts. Specifically, in the school context, intergroup contact can only reduce prejudice when parents are more involved in school affairs, which is in line with research on the contact hypothesis indicating that more meeting opportunities lead to reduced prejudice (Wagner et al. 2003). In addition, consistent with social learning theory (Bandura 1977), we find that prejudiced attitudes at the school level can be "contagious" through networks of students and parents. In the friendship context, we find that children's friendships with nonlocals can reduce the prejudice of their parents. This can be explained by the extended contact hypothesis indicating that perceiving in-group members' friendships with out-group members can significantly reduce prejudice (Zhou et al. 2018). However, this finding is only true for parents who do not know their children's nonlocal friends. It is possible that we found a floor effect for parents who already knew nonlocals and therefore already had lower prejudice at the first measurement point and could not go much lower while parents who did not know nonlocals and had higher levels of prejudice were able to reduce their prejudice, in line with the hypothesis. In the neighborhood context, we find that the effect of intergroup contact can vary among local families with different socioeconomic statuses: for families with higher SES, prejudice will increase as the number of nonlocal neighbors decreases; and for families with lower SES, prejudice will increase when there are more nonlocal neighbors. For higher SES people, this result is in line with the prediction but the opposite, namely, when there is a reduction in meeting opportunities prejudice increases. Next, inspired by previous research, we argue that unlike locals with higher SES, locals with a lower SES may compete with 
nonlocals in the same job market for scarce resources (e.g., employment), so they might feel threatened by the increase in the nonlocal population (Hello et al. 2006; Scheepers et al. 2002). This phenomenon echoes the necessity to pay attention to negative contact.

There are a few issues we were not able to address in this study, but could be of great value for future research. First, some scholars state that the search for ideal conditions of optimal contact seems to be utopian (Dixon et al. 2005) and question the effectiveness these microlevel interactions can have in macrolevel ethnic conflicts (Forbes 2004). Therefore, how intergroup contact at the microlevel affects societal-level conflict between locals and nonlocals in urban China is still a question for future research. Second, research on the contact hypothesis calls for a greater focus on negative contact (Pettigrew 2008), which has the risk of making group identification more salient and incurring intergroup conflicts (Barlow et al. 2012; Paolini et al. 2010). The results in this study also show that local families with lower SES may be more prejudiced against nonlocals because of intergroup contact. Therefore, the variability and quality of contact should be treated more carefully with specific indicators in future studies. The mechanisms behind families with lower SES having increased prejudice when there are more nonlocal neighbors can be further explored. According to previous research, perceived threat is proven to be the most important explanatory factor of why more educated people have less prejudice towards migrants (Hello, Scheepers, and Sleegers 2006). Another study has shown that urban residents with higher SES have lower levels of prejudice towards rural-tourban migrants, which is beneficial for their intergroup contact; and this link is moderated by urban residents' perceptions of migrants' social integration (Yang et al. 2010). Future studies can explore more mediators or interaction effects in the relationship between families with low SES in neighborhoods and the effect of intergroup contact on prejudice.

In conclusion, in this study on China, we focused on the role of intergroup meeting opportunities of local urban parents for their prejudice towards migrant people in the contexts of friendships, schools, and neighborhoods. Our findings show the importance of meeting opportunities for shaping intergroup contact between local urban residents and nonlocal migrants. Mostly, intergroup contact reduces intergroup prejudice; however, depending on the conditions, it also has the potential to lead to more prejudice. Apart from the theoretical implications, this study also provides new insights for policy makers: in order to reduce intergroup prejudice between local urban residents and nonlocal migrants, schools mixed with local and nonlocal students should create more opportunities for parents to be involved in school affairs and meet more nonlocal parents. For example, schools should provide meeting opportunities through parentteacher meetings and open days at schools and educate students about the importance of ethnic equality. Furthermore, governments should pay more attention to job and housing security for low SES families, which could reduce the perceived threats locals may experience and thus prevent prejudice towards migrants.

\section{References}

Allison, Paul. 2002. Missing Data. Thousand Oaks, CA: Sage. 
Allport, Gordon W. 1954. The Nature of Prejudice. MA: Addison-Wesley.

Amichai-Hamburger, Yair, and Katelyn McKenna. 2006. "The Contact Hypothesis Reconsidered: Interacting Via the Internet." Journal of Computer-Mediated Communication 11(3): 825-43.

Amir, Yehuda. 1969. "Contact Hypothesis in Ethnic Relations." Psychological Bulletin 71(5): 319-42.

Bandura, Albert, and David C. McClelland. 1977. Social Learning Theory. NJ: Prentice-Hall.

Barlow, Fiona Kate, Stefania Paolini, Anne Pedersen, Matthew J. Hornsey, Helena R. M. Radke, Jake Harwood, Mark Rubin, and Chris G. Sibley. 2012. "The Contact Caveat." Personality and Social Psychology Bulletin 38(12): 1629-43.

Brown, Rupert. 2010. Prejudice: Its Social Psychology. NJ: Wiley-Blackwell.

Chen, Guohua. 2008. "Chengshi Gongli Xuexiao Jiaoshi Dui Liudongrenkou Zinv Jiaoyu De Renzhi." Qingnian Yanjiu (6): 44-48.

Christakis, Nicholas, and James Fowler. 2013. "Social Contagion Theory: Examining Dynamic Social Networks and Human Behavior." Statistics in Medicine 32(4): 556-77.

Crisp, Richard, and Rhiannon Turner. 2009. "Can Imagined Interactions Produce Positive Perceptions? Reducing Prejudice through Simulated Social Contact." The American Psychologist 64(4): 231-40.

Datu, Jesus Alfonso. 2017. "Happy Classes Make Happy Students: Classmates' Well-Being Predicts Individual Student Well-Being." Journal of School Psychology 65: 116-28.

Dixon, John, Kevin Durrheim, and Colin Tredoux. 2005. "Beyond the Optimal Contact Strategy: A Reality Check for the Contact Hypothesis." The American Psychologist 60(7): 697711.

Dohmen, Thomas, Armin Falk, David Huffman, and Uwe Sunde. 2011. "The Intergenerational Transmission of Risk and Trust Attitudes." The Review of Economic Studies 79(2): 64577.

Du, Huimin, Jing Song, and Si-ming Li. 2020. "'Peasants Are Peasants': Prejudice against Displaced Villagers in Newly-Built Urban Neighbourhoods in China." Urban Studies. Advance online publication.

Ellison, Christopher G., Heeju Shin, and David L. Leal. 2011. "The Contact Hypothesis and Attitudes toward Latinos in the United States." Social Science Quarterly 92(4): 938-58.

Fan, C. Cindy. 1999. "Migration in a Socialist Transitional Economy: Heterogeneity, Socioeconomic and Spatial Characteristics of Migrants in China and Guangdong Province." International Migration Review 33(4): 954-87.

Feng, Wang, Xuejin Zuo, and Danching Ruan. 2002. "Rural Migrants in Shanghai: Living under the Shadow of Socialism." International Migration Review 36(2): 520-45.

Forbes, Hugh. 2004. "Ethnic Conflict and the Contact Hypothesis." In The Psychology of Ethnic and Cultural Conflict, edited by Yueh-Ting Lee, Clark McCauley, Fathali M. Moghaddam, and Stephen Worchel, 69-88. CA: Praeger Publishers/Greenwood Publishing Group.

Guang, Lei. 2005. "The State Connection in China's Rural-Urban Migration." International Migration Review 39(2): 354-80.

Hello, Evelyn, Peer Scheepers, and Peter Sleegers. 2006. "Why the More Educated Are Less Inclined to Keep Ethnic Distance: An Empirical Test of Four Explanations." Ethnic and 
Racial Studies 29(5): 959-985.

Hewstone, Miles, Ed Cairns, Alberto Voci, Stefania Paolini, Frances McLernon, Richard Crisp, Ulrike Niens, and Jean Craig. 2005. "Intergroup Contact in a Divided Society: Challenging Segregation in Northern Ireland." In The Social Psychology of Inclusion and Exclusion, edited by Dominic Abrams, Michael A. Hogg, and José M. Marques, 265-292. Philadelphia: Psychology Press.

Kende, Judit, Karen Phalet, Wim Van den Noortgate, Aycan Kara, and Ronald Fischer. 2018.

"Equality Revisited: A Cultural Meta-Analysis of Intergroup Contact and Prejudice." Social Psychological and Personality Science 9(8): 887-95.

King, Ronnel B. 2020. "Mindsets Are Contagious: The Social Contagion of Implicit Theories of Intelligence among Classmates." British Journal of Educational Psychology 90(2): 349-63.

Kwong, Julia. 2011. "Education and Identity: The Marginalisation of Migrant Youths in Beijing." Journal of Youth Studies 14(8): 871-83.

Laar, Colette, Shana Levin, Stacey Sinclair, and Jim Sidanius. 2005. "The Effect of University Roommate Contact on Ethnic Attitudes and Behavior." Journal of Experimental Social Psychology 41(4): 329-45.

Lan, Pei-chia. 2014. "Segmented Incorporation: The Second Generation of Rural Migrants in Shanghai." The China Quarterly 217: 243-65.

Li, Nanshou. 2018. "How Many Migrant and Left-Behind Children Are There in China?" Urbanization Observation Network (Chengshihua Guancha Wang), February 5, 2021, https://www.thepaper.cn/newsDetail forward 2351776.

Li, Sensen, Changquan Long, Qingfei Chen, and Hong Li. 2010. "Qunji Jiechu Lilun -- Yizhong Gaishan Qunji Guanxi De Lilun." Xinli Kexue Jinzhan 18(05): 129-37.

Li, Xiaoming, Bonita Stanton, Xiaoyi Fang, and Danhua Lin. 2006. "Social Stigma and Mental Health among Rural-to-Urban Migrants in China: A Conceptual Framework and Future Research Needs." World Health \& Population 8(3): 14-31.

Ling, Minhua. 2015. "“Bad Students Go to Vocational Schools!": Education, Social Reproduction and Migrant Youth in Urban China." The China Journal 73: 108-31.

Lu, Yao, and Hao Zhou. 2013. "Academic Achievement and Loneliness of Migrant Children in China: School Segregation and Segmented Assimilation." Comparative Education Review 57(1): 85-116.

McLaren, Lauren. 2003. "Anti-Immigrant Prejudice in Europe: Contact, Threat Perception, and Preferences for the Exclusion of Migrants." Social Forces 81(3): 909-36.

Mendoza, Norman. 2020. "The Social Contagion of Student Engagement in School." School Psychology International 41(5): 454-74.

Nieuwenhuis, Jaap, and Pieter Hooimeijer. 2016. "The Association between Neighbourhoods and Educational Achievement, a Systematic Review and Meta-analysis." Journal of Housing and the Built Environment 31(2): 321-47.

Nieuwenhuis, Jaap, Tom Kleinepier, and Maarten van Ham. 2021. "The role of exposure to neighborhood and school poverty in understanding educational attainment." Journal of Youth and Adolescence. Advance online publication.

Nieuwenhuis, Jaap, Beate Völker, and Henk Flap. 2013. ""A Bad Neighbour Is as Great a Plague as a Good One Is a Great Blessing": On Negative Relationships between 
Neighbours." Urban Studies 50(14): 2904-21.

Pan, Zequan. 2007. "Shehui Fenlei Yu Qunti Fuhao Bianjie: Yi Nongmingong Shehui Fenlei Wenti Wei Li." Shehui 27(4): 54-73+212.

Paolini, Stefania, Jake Harwood, and Mark Rubin. 2010. "Negative Intergroup Contact Makes Group Memberships Salient: Explaining Why Intergroup Conflict Endures." Personality \& Social Psychology Bulletin 36(12): 1723-38.

Pettigrew, Thomas. 2008. "Future Directions for Intergroup Contact Theory and Research." International Journal of Intercultural Relations 32(3): 187-99.

. 1997. "Generalized Intergroup Contact Effects on Prejudice." Personality and Social Psychology Bulletin 23(2): 173-85.

Pettigrew, Thomas, and Linda Tropp. 2008. "How Does Intergroup Contact Reduce Prejudice? Meta-Analytic Tests of Three Mediators." European Journal of Social Psychology 38(6): 922-34.

. 2006. "A Meta-Analytic Test of Intergroup Contact Theory." Journal of Personality and Social Psychology 90(5): 751-83.

Poteat, Paul, Dorothy Espelage, and Harold Green. 2007. "The Socialization of Dominance: Peer Group Contextual Effects on Homophobic and Dominance Attitudes." Journal of Personality and Social Psychology 92(6): 1040-50.

Scheepers, Peer, Mérove Gijsberts, and Marcel Coenders. 2002. "Ethnic Exclusionism in European Countries Public Opposition to Civil Rights for Legal Migrants as a Response to Perceived Ethnic Threat." European Sociological Review 18(1): 17-34.

Sherif, Muzafer, O. J. Harvey, William R. Hood, Carolyn W. Sherif, and Jack White. 1988. The Robbers Cave Experiment: Intergroup Conflict and Cooperation. CT: Wesleyan University Press.

Solinger, Dorothy J. 1999. Contesting Citizenship in Urban China: Peasant Migrants, the State, and the Logic of the Market. CA: University of California Press.

Stephan, Walter. 1978. "School Desegregation: An Evaluation of Predictions Made in Brown V. Board of Education." Psychological Bulletin 85(2): 217-38.

Stephan, Walter, Rolando Loving, and Anne Duran. 2000. "Integrated Threat Theory and Intercultural Attitudes Mexico and the United States." Journal of Cross-Cultural Psychology 31(2): 240-49.

Tajfel, Henri. 1982. "Social Psychology of Intergroup Relations." Annual Review of Psychology 33(1): 1-39.

Tajfel, Henri, and John Turner. 1986. The Social Identity Theory of Inter-Group Behavior. Chicago: Nelson-Hall Publishers.

Turner, Rhiannon, Miles Hewstone, Alberto Voci, and Christiana Vonofakou. 2008. "A Test of the Extended Intergroup Contact Hypothesis: The Mediating Role of Intergroup Anxiety, Perceived Ingroup and Outgroup Norms, and Inclusion of the Outgroup in the Self." Journal of Personality and Social Psychology 95(4): 843-60.

UNICEF. 2017. "Figure 1.18 Migrant Population, 1982-2017." UNICEF China, February 5, 2021, https://www.unicef.cn/en/figure-118-migrant-population-19822017.

Valentine, Gill. 2008. "Living with Difference: Reflections on Geographies of Encounter." Progress in Human Geography 32(3): 323-37.

Wagner, Ulrich, Rolf Dick, Thomas Pettigrew, and Oliver Christ. 2003. "Ethnic Prejudice in 
East and West Germany: The Explanatory Power of Intergroup Contact." Group Processes \& Intergroup Relations 6(1): 22-36.

Wagner, Ulrich, Miles Hewstone, and Uwe Machleit. 1989. "Contact and Prejudice between Germans and Turks: A Correlational Study." Human Relations 42(7): 561-74.

Wang, Lu. 2008. "The Marginality of Migrant Children in the Urban Chinese Educational System." British Journal of Sociology of Education 29(6): 691-703.

Wang, Tao. 2020. "Rural Migrants in China: Barriers to Education and Citizenship." Intercultural Education 31(5): 578-91.

Wright, Stephen, Arthur Aron, Tracy McLaughlin-Volpe, and Stacy Ropp. 1997. "The Extended Contact Effect: Knowledge of Cross-Group Friendships and Prejudice." Journal of Personality and Social Psychology 73(1): 73-90.

Yang, Huadong, Lili Tian, Jan Pieter van Oudenhoven, Jacomijn Hofstra, and Qing Wang. 2010. "Urban Residents' Subtle Prejudice Towards Rural-to-Urban Migrants in China: The Role of Socioeconomic Status and Adaptation Styles." Journal of Community \& Applied Social Psychology 20(3): 202-16.

Zhou, Shelly, Elizabeth Page-Gould, Arthur Aron, Anne Moyer, and Miles Hewstone. 2018. "The Extended Contact Hypothesis: A Meta-Analysis on 20 Years of Research." Personality and Social Psychology Review 23(2): 132-60. 


\section{Figures}

Figure 1. Average levels of prejudice by context $(\mathrm{N}=1,630)$.

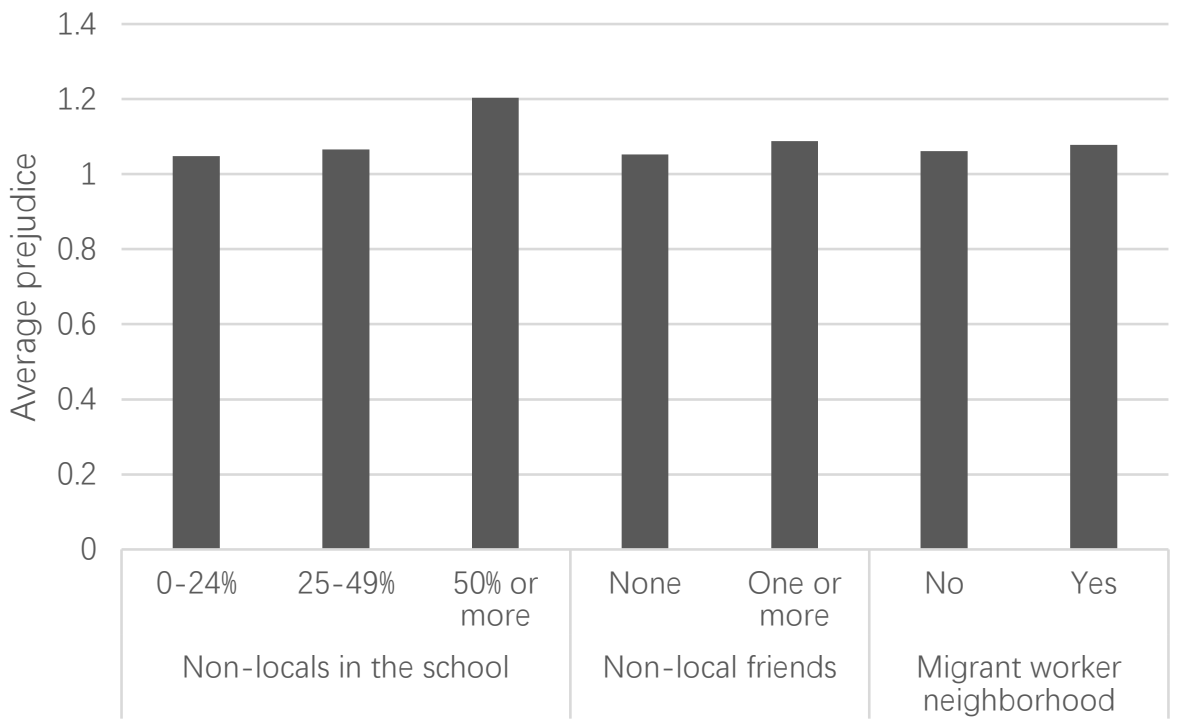

Note: Prejudice is measured as the average of both prejudice variables at wave 1: prejudice about how non-local students affect the educational quality and the atmosphere at school. 


\section{Tables}

Table 1. Descriptive statistics

\begin{tabular}{llllll}
\hline & $\mathrm{N}$ & Mean & SD & Min. & Max. \\
\hline Change in prejudice about educational quality & 1,630 & -.04 & .58 & -2 & 2 \\
Change in prejudice about atmosphere & 1,630 & -.04 & .59 & -2 & 2 \\
More non-local students in school & 1,630 & 3.03 & 19.58 & -35 & 67 \\
Student has more non-local friends & 1,630 & -.11 & 1.18 & -5 & 5 \\
Parental involvement in school & 1,628 & 1.35 & .99 & 0 & 3 \\
School-level change in prejudice about educational quality & 1,630 & -.06 & .09 & -.36 & 1 \\
School-level change in prejudice about atmosphere & 1,630 & -.05 & .09 & -1 & .18 \\
Highest achieved education & 1,630 & 4.96 & 2.12 & 1 & 9 \\
Student age & 1,630 & 12.83 & .61 & 10.83 & 17.17 \\
& & Prop. & & & \\
Change in migrants in neighborhood & & & & & \\
- Fewer migrants & 1,630 & .18 & & & \\
- Stable & 1,630 & .77 & & & \\
- More migrants & 1,630 & .05 & & & \\
Parents know students' friends' parents & 1,503 & .72 & & & \\
Agricultural hukou (ref.: non-agricultural hukou) & 1,630 & .28 & & & \\
Family SES & & & & & \\
- Poor & 1,630 & .11 & & & \\
- Middle & 1,630 & .80 & & & \\
- Rich & 1,630 & .08 & & & \\
Sex: male & 1,630 & .40 & & & \\
Student sex: male & 1,630 & .49 & & & \\
\hline
\end{tabular}


Table 2. Regressions for local residents' changes in prejudice about how non-local students affect the educational quality and the atmosphere at school $(\mathrm{N}=1,630)$.

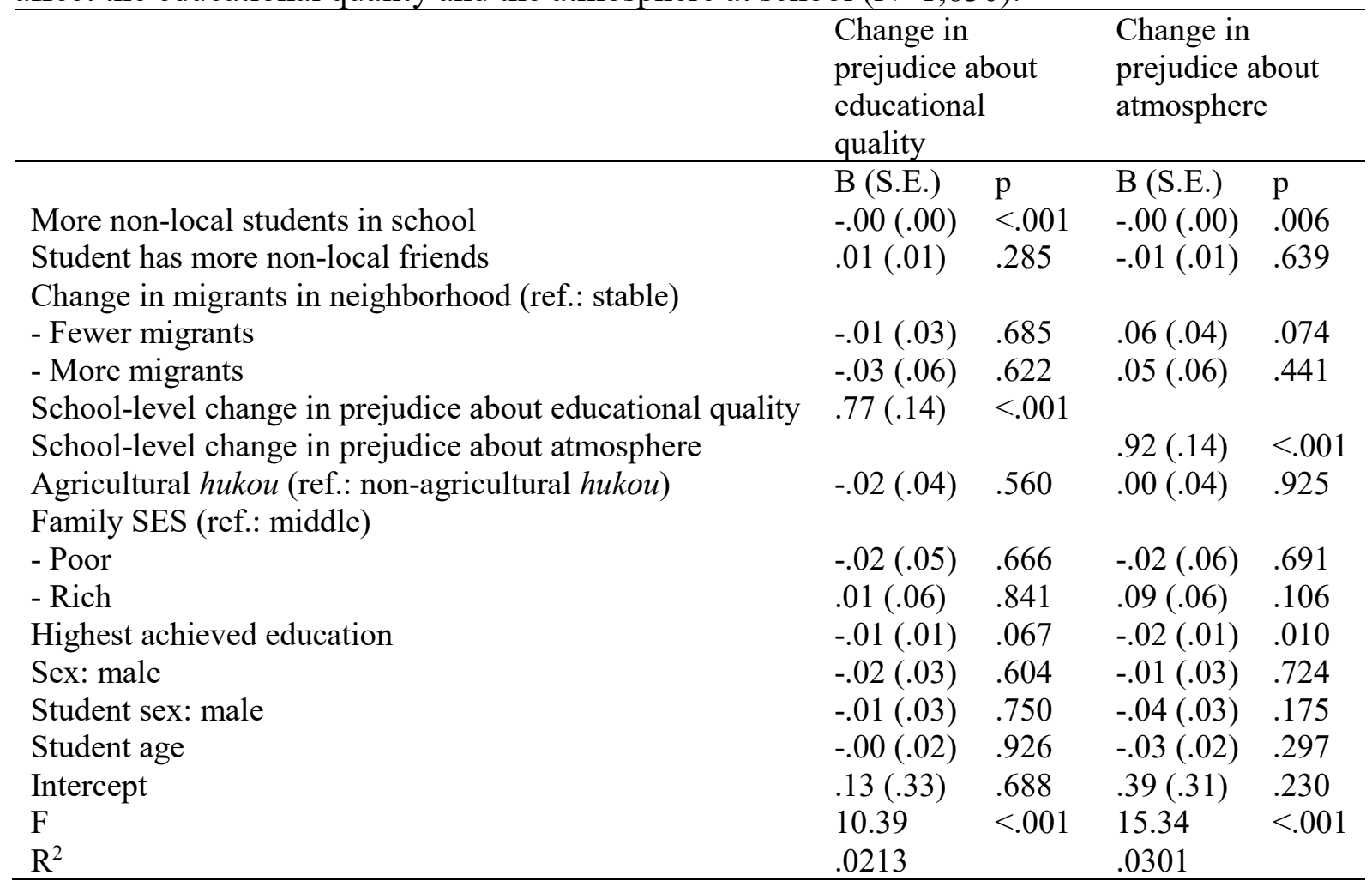

Note: The standard errors are adjusted for clustering in 73 schools. 
Table 3. Interaction effects for local residents' changes in prejudice about how non-local students affect the educational quality.

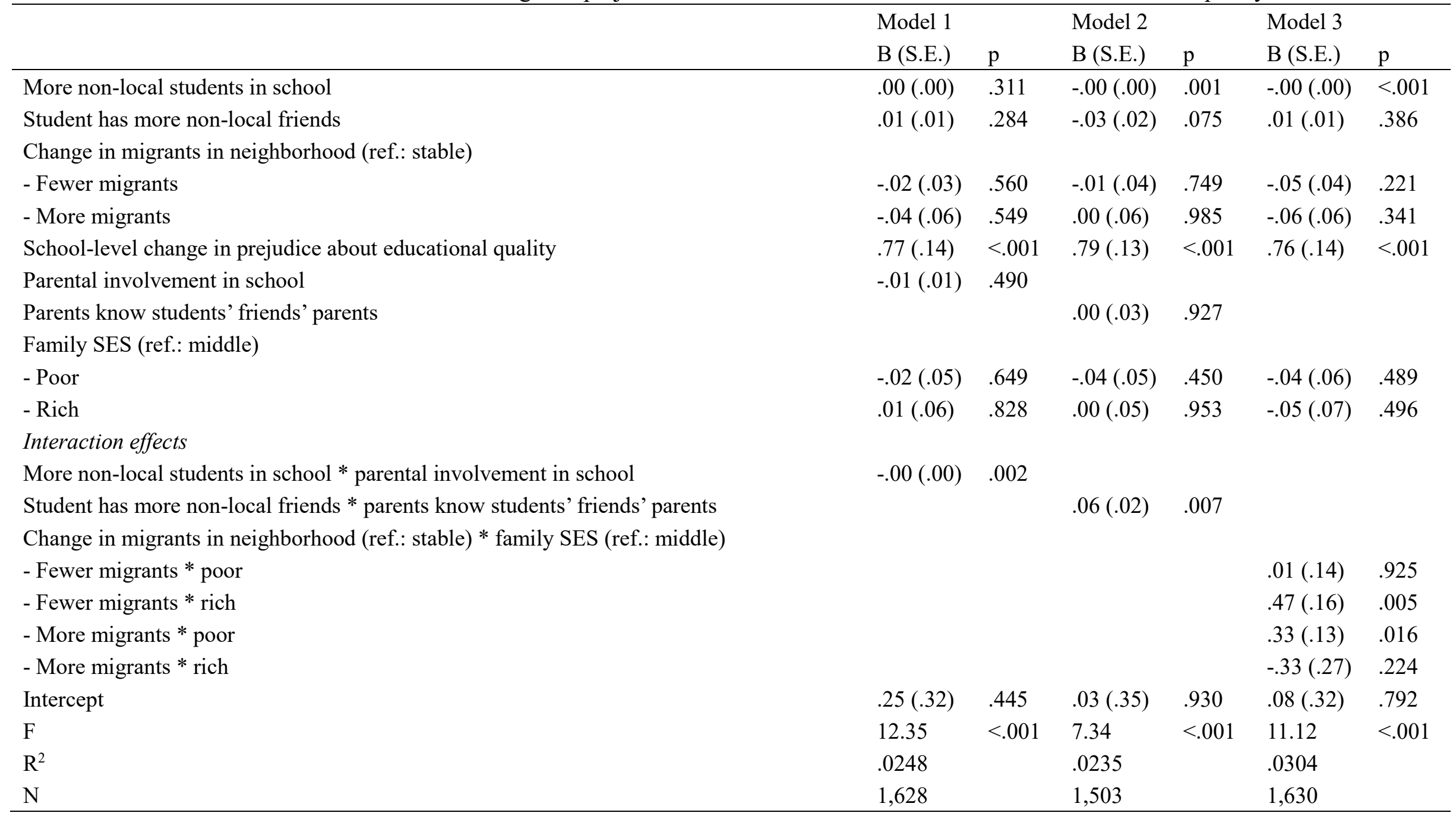

Notes: The standard errors are adjusted for clustering in 73 schools. Present in the regression, but omitted from the table are: agricultural hukou, highest achieved education, sex, student sex, and student age. 
Table 4. Interaction effects for local residents' changes in prejudice about how non-local students affect the atmosphere at school.

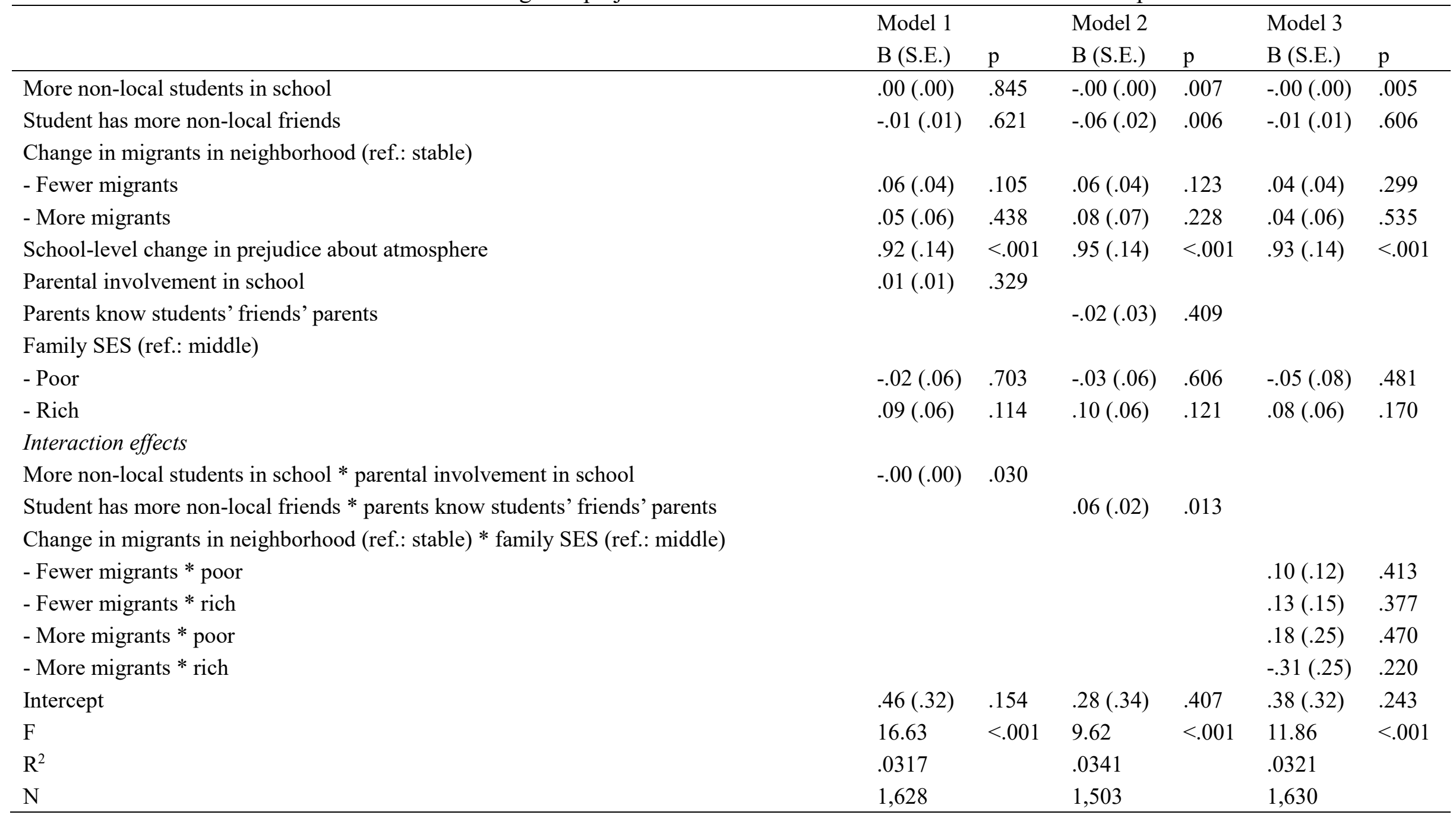

Notes: The standard errors are adjusted for clustering in 73 schools. Present in the regression, but omitted from the table are: agricultural hukou, highest achieved education, sex, student sex, and student age. 